\title{
RAZÃo PRÁTICA ENTRE DESEJO E BENS HUMANOS BÁSICOS. A CRÍTICA METAÉTICA DE JOHN FINNIS AO EMOTIVISMO E CETICISMO
}

\author{
PRACTICAL REASON BETWEEN DESIRE AND BASIC HUMAN GOODS. THE METAETHICAL \\ CRITIQUE OF JOHN FINNIS TO EMOTIVISM AND SKEPTICISM
}

\author{
Victor Sales Pinheiro* \\ Dienny Magalhães Riker Pereira**
}

\begin{abstract}
RESUMO
John Finnis é considerado o maior filósofo da nova teoria da lei natural, na teoria da lei natural, que renova a tradição da ética clássica de Aristóteles e Aquino, confrontando-os com os modernos, principalmente com Hobbes, Hume, Kant e Nietzsche. Este Artigo aborda, especificamente, a sua concepção metaética de razão prática. Para tanto, reconstitui a sua crítica ao emotivismo e ao ceticismo modernos, oriundos principalmente de Hume. Na primeira parte, trata do reducionismo da razão prática a mero instrumento de efetivação de desejos subracionais. Na segunda, articula a dimensão racional dos desejos, relacionando-os aos bens inteligíveis a que eles se voltam. Na terceira, analisa a integração do sentimento à razão prática, explorando a alegoria da máquina de experiências, proposta por Robert Nozick. Por fim, na quarta parte, a partir da natureza da deliberação, apresenta o argumento da autorrefutação como crítica principal ao ceticismo moral. Na conclusão, percebe-se a consistência da teoria moral de Finnis e se atenta para a consequência jurídico-político das teorias restritivas do bem humano, baseadas no emotivismo e ceticismo.
\end{abstract}

PALAVRAS-CHAVE: Metaética. Razão prática. Bens humanos. Emotivismo. Ceticismo.

\section{ABSTRACT}

John Finnis is considered the greatest philosopher of the new natural law theory, which renews the tradition of classical ethics of Aristotle and Aquinas by confronting them with modern philosophers, such as Hobbes, Hume, Kant, and Nietzsche. This paper deals specifically with his metaethical conception of practical reason. To this end, it reconstitutes his critique of modern emotivism and skepticism, derived mainly from Hume. In the first part, it deals with the reductionism of practical reason to a mere instrument of realization of subrational desires. In the second, it articulates the rational dimension of desires, relating them to the intelligible goods to which they turn. In the third, it analyzes the integration of feeling into practical reason, exploring the allegory of the experience machine proposed by Robert Nozick. Finally, in the fourth part, starting from an analysis of the nature of deliberation, it presents the argument of self-refutation as the main objection to moral skepticism. In conclusion, it recognizes the consistency of Finnis' moral theory and points to the juridical-political consequence of restrictive theories of human good, based on emotionalism and skepticism.

KEYWORDS: Metaethics. Practical reason. Basic goods. Emotivism. Skepticism.

\footnotetext{
* Mestre em Filosofia pela PUC-RIO. Doutor em Filosofia pela UERJ. Professor Adjunto da Universidade Federal do Pará (UFPA). Coordenador do Grupo de Pesquisa (CNPq) "Tradição da Lei Natural". Email: vvspinheiro@yahoo.com.br.

** Mestre em Direito pelo Programa de Pós-graduação em Direito da Universidade Federal do Pará (PPGD/UFPA). Pesquisadora no Grupo de Pesquisa (CNPq) "Tradição da Lei Natural". E-mail: deriker.adv@gmail.com.
} 
Artigo: Razão prática entre desejo e bens humanos básicos. A crítica metaética de John Finnis ao emotivismo e ceticismo

\section{INTRODUÇÃO}

É possível conhecer o fundamento da ação humana? Os fins e os bens que estruturam a ação moral são objetivos e inteligíveis ou frutos de emoções subjetivas incomensuráveis pela razão, valorações pessoais insuscetíveis de serem conhecidas objetiva e intelectualmente? Em outras palavras, o fundamento filosófico da ação moral é um bem objetivo ou um valor subjetivo? Esse bem ou valor pode ser conhecido objetivamente? Ele concerne a uma inclinação inscrita na própria natureza humana racional ou é fruto de uma construção social contingente? A conduta moral é resultante de desejos ou repousa num fundamento racional objetivo?

Essas são algumas das perguntas metaéticas centrais, fundamentais, a que nenhum filósofo moral pode se furtar. São questões de segunda ordem que refletem sobre os fundamentos das questões éticas de primeira ordem, que são os dilemas práticos da ética normativa. A metaética estuda o juízo ético na sua dimensão teórica, epistemológica: "a metaética é o estudo descritivo do discurso e da prática da ética [normativa]. Não se trata [...] de encontrar respostas à questão 'como devemos viver?', mas, [...] de compreender melhor como funcionam os conceitos que mobilizamos na formulação da questão ética" (MENDONÇA, 2014, p. 153).

De fato, a filosofia contemporânea, sobretudo a tradição analítica anglo-saxã, renovou essas indagações a partir do resgate da tradição clássica de Aristóteles (2007) e Tomás de Aquino (2010), em filósofos como E. Anscombe (2005), A. MacIntyre (2001) e J. Finnis (2011a). O resultado é um fértil debate metaético acerca dos fundamentos teóricos da ética, que gravita em torno da órbita ontológica da objetividade dos bens morais e epistemológica da inteligibilidade deles. Nesse diapasão, desdobram-se tendências objetivistas e subjetivistas, realistas e construtivistas, cognitivistas e não-cognitivistas, conforme a classificação adotada.

Robert Alexy (1994, p. 133), por exemplo, distingue concepções aristotélicas, hobbesianas, kantianas e nietzschinas de razão prática, distinção essa que Massini Correas (2006, p. 184-188) desenvolve, respectivamente, como realistas, instrumentais, transcendentais construtivistas e irracionalistas. Por sua vez, Ferreira Neto (2015) propõe seis tradições metaéticas fundamentais: amoralismo, emotivismo, subjetivismo, relativismo moral, construtivismo e realismo, enfocando-as a partir da dialética cognitivismo e não-cognitivismo (ceticismo). Vigo (2015) é outro teórico preocupado com a dimensão metaética da democracia, contrapondo o objetivismo cognitivista ao ceticismo relativista. 
No contexto desse debate metaético, a questão do ceticismo moral é, certamente, uma das mais relevantes da ética filosófica. Desde o robusto enfrentamento de Platão aos sofistas, na defesa de um conhecimento objetivo das formas das virtudes que apontam para a racionalidade dos fins que legitimam as ações individuais e sociais (RIST, 2002), até a defesa moderna da impossibilidade de assegurar, dogmaticamente, tal conhecimento moral (ANNAS; BARNES, 1985), nenhum filósofo moral furta-se à questão da inteligibilidade da ação moral, da possibilidade de conhecer os bens que a tornam valiosa e boa.

Na modernidade, David Hume (2009) é considerado o grande marco das tendências emotivistas, não-cognitivistas ou céticas na filosofia moral, embasando a tradição analítica da ética que desconfia da capacidade de a razão humana compreender os fundamentos inteligíveis da ação moral, reduzindo a razão moral à racionalização de desejos não-racionais.

Uma das respostas mais consistentes à tradição cética em geral e a Hume em particular é fornecida por John Finnis, um dos mais relevantes filósofos dos nossos dias, renovando a ética clássica de Aristóteles e Aquino em linguagem analítica. Autor de obra volumosa no campo da Filosofia Prática, sobretudo da Ética e do Direito, esse professor de Oxford é o maior expoente da Teoria Neoclássica da Lei Natural, valiosa por articular, a partir de um conceito teleológico de razão prática, a ética dos bens humanos básicos com o direito do bem comum que fornece o horizonte social de sua realização (KEOWN; GEORGE, 2013).

Ao apresentar, sinteticamente, a sua teoria para um público mais amplo, no verbete 'Natural Law' redigido para o Dicionário de Ética e Filosofia Moral organizado por Sperber, Finnis (2011f, p. 201-205) afirma que uma teoria da lei natural, baseada nos clássicos da tradição central da ética ocidental - Platão, Aristóteles e Aquino - compreende uma crítica filosófica aos ceticismos éticos (seja niilismo, relativismo, subjetivismo, positivismo ou hedonismo, como os de Hobbes, Hume, Nietzsche e Weber), a partir sobretudo do argumento da autorrefutação. Essa teoria tem caráter cognitivista ou objetivista, por quatro motivos: (1) investigação de bens humanos básicos, como vida e saúde, conhecimento e amizade, que realizam o florescimento humano, bens esses que são o núcleo substantivo dos primeiros princípios do raciocínio prático; (2) identificação desses bens por insight, cujo conteúdo são os princípios autoevidentes da razão prática, dos quais derivam juízos morais específicos; (3) reconhecimento da incomensurabilidade desses bens humanos básicos, rechaçando teorias agregativas, utilitaristas ou consequencialistas que os instrumentalizam por cálculos de interesse; (4) análise epistemológica da teoria social descritiva que, pelo método analógico, 
Artigo: Razão prática entre desejo e bens humanos básicos. A crítica metaética de John Finnis ao emotivismo e ceticismo

contribua, normativamente, para a razoabilidade das instituições sócias enfocadas, mediante a seleção dos "casos centrais" relevantes para a autocompreensão e avaliação dessas práticas.

Seu ponto de partida, portanto, é a releitura da razão prática tomista proposta por Germain Grisez (1965), visando (1) superar a falácia naturalista que neutralizou o estudo da lei natural na modernidade e (2) demonstrar como o primeiro princípio da razão prática não é moral, mas indispensável a todo e qualquer raciocínio prático indistintamente.

Finnis absorve essa leitura e desenvolve essa reformulação da razão prática argumentando em um debate ainda mais arraigado na modernidade: qual seja, o emotivismo, subjetivismo e hedonismo ético ${ }^{1}$ e sua relação com o ceticismo metaético.

Desde o início de sua produção filosófica - hoje disponível na edição dos seus Ensaios Reunidos em cinco volumes -, Finnis preocupa-se com a inconsistência filosófica do ceticismo pelo argumento da autorrefutação, como no artigo 'Scepticism Self-Refutation', de 1977 (FINNIS, 2011c). Esse argumento será sucessivamente renovado ao longo de sua teorização, sobretudo nas suas obras-primas, Lei natural e direitos naturais (FINNIS, 2011a) e Aquinas (FINNIS, 1996), sem prejuízo do livro Fundamentos de ética (FINNIS, 2012) e dos artigos 'Self-refutation revisited' (FINNIS, 2011d) e 'Natural law' (2011f). Ou seja, esse tema é enfrentado ao longo dos últimos quarenta anos de sua obra.

Para Finnis, a investigação metaética acerca dos fundamentos da razão prática e da inteligibilidade dos bens humanos básicos, que indicam as inclinações racionais de pessoas humanas livres e racionais, responde à insuficiência do ceticismo moral subjacente às teorias sociais normativas, principalmente a do positivismo jurídico e a do liberalismo político, cujos apelos à pureza epistemológica da teoria jurídica e à neutralidade moral da teoria política baseiam-se num relativismo, subjetivismo e niilismo, ainda que não admitidos (FINNIS, 2011h, p. 87). Ou seja, a reflexão ética de Finnis volta-se sempre à sua dimensão jurídica e política, pensando a razão prática na sua dimensão de razão pública de consecução do bem comum, para realização das condições sociais do florescimento humano (GEORGE, 1993).

Este artigo reconstitui a crítica de Finnis ao emotivismo e ceticismo moral, em quatro partes. Na primeira, apresenta em que consiste a inteligibilidade do bem humano como razão última e suficiente para ação. Na segunda e terceira, trata, respectivamente, do papel do desejo e do sentimento em relação à ação racional. Na quarta, analisa a deliberação racional e

\footnotetext{
${ }^{1} \mathrm{Na}$ influente obra Depois da virtude, MacIntyre (2001) considera o emotivismo - que compreende o subjetivismo e o ceticismo - a tendência predominante da prática moral e da teorização ética da modernidade (MAHON, 2013).
} 
a dimensão autorrefutatória do ceticismo moral. Na quinta e última, explica o motivo de certas teorias morais serem reducionistas, restritivas em relação ao bem humano racional. Por fim, conclui pela consistência do argumento de Finnis, assim como pela sua relevância no âmbito da razão prática moral e jurídico-política.

\section{O REDUCIONISMO DA RAZÃO PRÁTICA À RACIONALIZAÇÃO DE DESEJOS SUB-RACIONAIS}

Na compreensão realista clássica de Finnis (2012, p. 27), o argumento cético moderno tem sua expressão histórica originária em Hobbes e culmina na teoria moral de Hume. Para Hobbes, os termos "bem" e "mal” são meras expressões de relação entre as coisas e os desejos de quem os pronuncia. Hume, por sua vez, claramente nega a objetividade da moralidade afirmando que "a moralidade é determinada pelo sentimento. [...] a virtude [é] qualquer ação mental ou qualidade que dê ao espectador o sentimento agradável de aprovação; e o vício é o seu contrário" (HUME, 2009, p. 497; FINNIS, 2012, p. 28).

Todavia, essa proposição de que a realidade moral é apenas a expressão de sentimentos não explica satisfatoriamente o fato de que as proposições morais não são expressas pelo agente e nem recebidas pelo interlocutor como algo referente a sentimentos. Antes, as proposições morais são expressas e assumidas como [1] sendo capazes de ser verdadeiras ou falsas; e [2] como sendo, intrinsecamente, guiadoras da ação (FINNIS, 2012, p. 28).

Pode ser encontrado em Hume um prenúncio de resposta a essa crítica em termos de objetificação, isto é, a recepção de proposições morais como sendo capazes de dirigir a conduta e serem verdadeiras seria resultado da projeção dos nossos sentimentos sobre as ações. Para Hume, as qualidades avaliativas (certo ou errado, bem ou mal) são feições ilusórias geradas na inter-relação de nossos sentimentos em situações sociais e repetidas ao ponto de, talvez, exercer um papel útil (FINNIS, 2012, p. 28).

Essa resposta, no entanto, é pautada em uma concepção restritiva da razão prática como incapaz de identificar bens inteligíveis e como instrumental para alcançar desejos subracionais. Entendemos que a teoria neoclássica da lei natural de Finnis oferece uma explanação e uma resposta mais adequada a essa questão, pois compreende e justifica a atuação da razão prática na determinação da conduta humana. 
Artigo: Razão prática entre desejo e bens humanos básicos. A crítica metaética de John Finnis ao emotivismo e ceticismo

Atualmente, uma alternativa influente que nega a verdade no campo objetivo da moralidade é a vertente metaética "não-cognitivista" que se resume à análise da linguagem e da lógica empregada no discurso moral. Nesse marco, Finnis destaca a filósofa Phillipa Foot, que dirigiu críticas pertinentes a esse tipo de visão metaética enquanto descrição da linguagem. Foot arguiu que as prescrições éticas, consideradas como proposições que poderiam ter qualquer conteúdo moral, independente da verdade ou bondade delas, na realidade estão intrinsecamente relacionadas, por meio das regras da linguagem, com os conceitos de importância, prejuízo e vantagem. Isso inviabiliza que sejam tomadas decisões totalmente arbitrárias sobre as considerações que devem valer como evidência na moral. Ou seja, o discurso moral posto não está sujeito a toda e qualquer arbitrariedade - não é viável, por exemplo, que a própria decisão pessoal de alguém determine "que bater palma três vezes por hora é uma virtude, enquanto a coragem não o é” (FINNIS, 2012, p. 29).

Entretanto, Finnis entende que o argumento de Foot não se afastou completamente do ceticismo de Hobbes e Hume, o qual não consiste em uma dúvida sobre as conexões entre juízos morais, linguagem moral e natureza humana. Antes, o cerne do argumento que Finnis deseja evidenciar e combater é a visão hobbesiana e humiana sobre o papel da razão, considerada uma habilidade de descobrir a verdade, na formação da nossa linguagem moral e dos nossos juízos, bem como na direção de nossas ações (FINNIS, 2012, p. 29).

Finnis rejeita a visão de que a razão prática funda-se em desejos pré-racionais, dos quais a única coisa que podemos dizer é que "nós o possuímos". Filósofos como John MacDowell e Thomas Nagel também chegaram a repudiar explicitamente essas alegações hobbesianas e humianas, porém não avançaram mais porque não chegaram a questionar em que sentido é simplesmente irrazoável a negação das razões últimas para ação, que estruturam as virtudes morais (FINNIS, 2012, p. 30). Ou seja, apesar de identificarem a forma restritiva como a razão prática é concebida por Hume e Hobbes, MacDowell e Nagel não conseguiram compreender a maneira como a razão prática realmente atua no campo das deliberações humanas, fornecendo critérios substantivos para a correção das ações morais, permitindo distinguir entre o bom e o mau, a virtude e o vício, o razoável e o desarrazoável.

Em relação à virtude da prudência, articulada por Aristóteles, Finnis discorda dos intérpretes que a consideram como meramente instrumental, como se a prudentia se relacionasse a meios e não a fins, uma vez que os fins seriam sub-racionais. Se fosse assim, a razão prática atuaria a partir de (e para) desejos irracionais, e seria consonante com a ética humiana. 
Segundo Finnis (2012, p. 33) essa interpretação instrumentalista não procede. A afirmação de Aristóteles (2007, p. 179) de que a deliberação é sobre os meios e não sobre os fins não indica que os fins básicos da ação são fornecidos por desejos simplesmente possuídos ou que são apresentados pela natureza humana. Ao contrário, a partir de uma leitura mais atenta do texto aristotélico, Finnis considera que os fins da ação são encontrados por meio do direcionamento da inteligência à apreensão de certos objet(iv)os como realmente bons. Isso porque a deliberação é, precisamente, a razão humana prática em atividade, em todo o seu alcance, tanto instrumental (eleição dos meios eficazes para a consecução dos fins), quanto finalístico (discernimento dos fins que conduzem à felicidade, ao florescimento).

A teleologia artistotélica relaciona-se, assim, a ambos, aos fins racionais da ação, cuja realização caracteriza a ação virtuosa que promove a felicidade, e aos meios eficazes para alcançá-los (FINNIS, 2011e). A interpretação instrumentalista da virtude da prudência aristotélica corresponde mais à noção moderna do ceticismo e utilitarismo, criticados por Finnis como teorias restritivas da razão prática.

\section{A RAZOABILIDADE DOS DESEJOS POR BENS INTELIGÍVEIS}

Como a interpretação finnisiana de Aristóteles é baseada em Tomás de Aquino, ele precisa afastar as compreensões modernas de que o grande filósofo clássico seria um subjetivista na ética, mais afeito a Hume do que a Aquino. Ao contrário, Finnis defende a dimensão realista e finalística da ética de Aristóteles, contra as visões reducionistas de razão prática que o deturpam (GEORGE, 1993).

Com efeito, existe um abismo entre a ética aristotélica e a humiana. As confusões na interpretação do funcionamento da razão prática surgem da seguinte forma: as pessoas agindo voluntariamente estão motivadas por uma razão para a ação, que parte da concepção de um bem a ser alcançado pela ação. Porque estão motivadas, dizem que desejam agir assim. $\mathrm{O}$ erro está na identificação desse desejo com o desejo pré-racional que alguns filósofos acreditam fornecer a base para o raciocínio prático. Em outras palavras, o desejo funda-se na bondade do fim (bem) visado pela razão. É a bondade objetiva do fim que o torna subjetivamente desejável. Não é o desejo subjetivo que confere bondade moral ao fim da ação. Mas é a bondade objetiva do fim que o torna atraente primeiro à razão prática, depois ao desejo por ela informado (GRISEZ; FINNIS; BOYLE, 1987). 
Artigo: Razão prática entre desejo e bens humanos básicos. A crítica metaética de John Finnis ao emotivismo e ceticismo

Os desejos são baseados no entendimento prático, que consiste na habilidade do indivíduo de entender razões para a ação. É esse entendimento que apreende os primeiros princípios da lei natural que são as razões últimas da ação humana (FINNIS, 1998, p. 79; 2012, p. 36). Os objetos últimos que motivam a ação humana captados pelo entendimento prático são os bens humanos básicos, desejáveis porquanto realizadores da natureza humana. Esses bens são apreendidos enquanto bens inteligíveis - razoáveis, inteligentemente desejáveis.

Ter "desejo por" ou simplesmente "querer algo" pode se referir seja (1) a objetivos isto é, às coisas que se quer receber, fazer, ter ou ser, e todas essas estão a certa distância; seja (2) a desejos atuais concebidos como estados atuais da pessoa, de sua psique ou experiências, que podem ser simplesmente satisfeitos. Note-se que a expressão satisfação, ou satisfeito, diferencia-se de satisfatório.

Satisfatório indica o que é adequado a um determinado objetivo. Os objetivos que os seres humanos inteligentemente almejam por meio do raciocínio prático não podem ser concebidos como sendo exclusivamente orientados para garantir satisfações (FINNIS, 2012, p. 32). Isso porque eles não são pautados em arbitrariedades subjetivas, mas em inteligibilidades de realização humana, oportunidades benéficas de participação em bens humanos reais ${ }^{2}$.

A perspectiva de satisfação de desejos falha em perceber o que é realmente importante sobre a ação humana. A compreensão da ação humana depende da pergunta "por que você está fazendo isso?”. A resposta a essa pergunta central aponta para o fim ao qual a ação está voltada. Pela compreensão desse fim, a ação se torna inteligível como uma oportunidade, como um bem, uma coisa boa para se fazer (FINNIS, 2012, p. 35). A razão é prática por identificar o desejável, tendo em vista a sua realização, de forma inteligente, a partir daquele momento. O fim desejável se apresenta como uma possibilidade favorável, uma ação possível, um bem a ser realizado. O raciocínio prático não começa, desse modo, com quereres (a serem satisfeitos), mas com a identificação de algo querido (o bem a ser perseguido e realizado) (FINNIS, 2012, p. 37).

\footnotetext{
2 A concepção metaética de "realidade moral" defendia pela teoria neoclássica de Finnis não é aquela de um "realismo platônico" (de entes não materiais situados num plano suprassensível, mas se aproxima a um "construtivismo objetivista", defendendo uma concepção robusta de verdade moral, a qual inclui princípios morais substantivos. Finnis (2012, p. 65) considera o realismo moral de tipo platônico uma confusão da ordem natural com a ordem moral. Sobre as quatros ordens da realidade - natural, lógica, ética e técnica - ver Finnis (1996, p. 20-23).
} 
Nem tudo pode ser inteligentemente querido ou considerado desejável, a menos que possa servir de fundamento teleológico da ação, de fim (telos) que a motive racionalmente. Segundo Finnis (2012, p. 35), os desejos se relacionam com concepções relevantes de possibilidades práticas tidas como oportunidades de realização de um bem, sendo "essas concepções que fornecem o motivo para agir, independentemente dos sentimentos que, qua sentimentos, predominantemente são obstáculos [para a ação]”.

Desse modo, o que a razão prática alcança é, em primeiro lugar, o bem inteligível e não apenas o bem experienciado. A razão prática possui um papel fundamental na formação de nossos juízos e na direção de nossas ações a partir da atratividade de bens inteligíveis. De fato, a compreensão adequada da ética depende da distinção entre o bem enquanto experienciado e o bem enquanto inteligível. Para tanto, é necessário reconhecer a diferença profunda entre a motivação emocional (e meramente senciente) e a motivação racional, sendo que a adequada percepção dessa diferença requer a compreensão prévia da independência inerente aos motivos racionais (razões para a ação). Além disso, a forma como esses motivos podem ser últimos depende da compreensão de como o entendimento capta as inteligibilidades referentes aos primeiros princípios da razão prática que se encontram na experiência (FINNIS, 1998, p. 77).

A apreensão dos primeiros princípios da razão prática se dá por meio do entendimento (understanding) constituído por atos de insight - por meio dos quais alguém apreende os conceitos e palavras com as quais pensa, se comunica e passa a conhecer o mundo de uma maneira bem mais profunda em relação às experiências fornecidas pelos sentidos. Não compreendemos sem experiência prévia do mundo que conhecemos primeiramente por meio dos sentidos. Não obstante, quando compreendemos apreendemos para além dos dados da experiência (MIRANDA, 2015).

As proposições, explícitas e implícitas, nas quais nossos conceitos e palavras alcançam seu significado pleno nos levam além do horizonte dos particulares dados na experiência para os universais, para os tipos, os gerais; para o verdadeiro, em oposição ao falso; e, pelo arrazoar (que é posterior ao entendimento), nos levam do causado para a causa, e assim por diante.

Por exemplo: uma pessoa não pode compreender que o conhecimento é um bem humano básico a não ser que tenha tido a experiência de especular e $s e . . .$, ou por quê...?. Essa pessoa tem um insight sobre a bondade intrínseca do conhecimento ao encontrar caminhos de resposta para seus próprios questionamentos, percebendo então que as respostas sugerem mais 
Artigo: Razão prática entre desejo e bens humanos básicos. A crítica metaética de John Finnis ao emotivismo e ceticismo

perguntas, e que podem ser verdadeiras, em oposição a falsas, e que as respostas podem ser compiladas como conhecimento, e que outras pessoas também compartilham essa habilidade e oportunidade.

Por um ato de insight, de entendimento que não é alcançado pelo encadeamento de um arrazoar, a pessoa alcança a proposição de que o conhecimento não é uma mera possibilidade, mas uma oportunidade, um bem. Esse insight não é uma inferência, ou dedução a partir de premissas, ou mesmo uma conclusão a partir das informações fornecidas pela experiência. Antes, o conhecimento é um novo conceito (FINNIS, 2011b, p. 2; 1998, p. 88-89).

Uma das principais influências de Finnis para a formação do conceito de insight foi Bernard Lonergan. Lonergan compreendeu a realidade e o poder do entendimento humano, mas não entendeu adequadamente o nosso entendimento prático, ou melhor, a relação deste último com o bem humano. Esse filósofo apresenta um esquema triádico de análise sobre a estrutura do entendimento humano nas operações intelectuais práticas não operacionais da ciência, da interpretação e do senso comum, composta por (1) experiência; (2) perguntas que levam a insights; e (3) perguntas reflexivas que levam a juízos racionais. A essa manifestação triádica das operações intelectuais de experiência, insight e juízo, corresponde a análise triádica dos níveis do bem.

No primeiro nível está o bem que é objeto do desejo - anterior a perguntas, intuições, reflexões e juízos. Quando é alcançado, é experienciado como prazeroso e satisfatório. No terceiro nível, está o bem que advém da reflexão e do juízo, da deliberação e da escolha. Já no segundo nível, está o bem que:

\footnotetext{
"enquanto é antecipado e refletido por uma intersubjetividade espontânea, é, essencialmente, uma inteligibilidade formal que é para ser descoberta apenas ao se suscitar perguntas, compreendidas apenas por meio de acúmulo de intuições, formuladas apenas em concepções", e que está, totalmente, fora do campo do apetite sensível: 'o bem inteligível. (FINNIS, 2012, p. 43, grifos nossos).
}

O bem inteligível, para Lonergan, é o bem da ordem, que consiste em um padrão inteligível de relações que condicionam a realização dos desejos individuais particulares por meio das contribuições para a realização dos desejos de outros. Assimilando criticamente Lonergan, Finnis entende que ele não conseguiu se desvencilhar do empirismo, subsistindo em seu pensamento um tipo de empirismo sofisticado (FINNIS, 2012, p. 44). Lonergan continua sendo um empirista porque a bondade parece estar localizada na satisfação dos 
desejos que um ser (humano) simplesmente acaba tendo e não nos aperfeiçoamentos que são obtidos, realizados e nos quais participa aquele ser que deseja (FINNIS, 2012, p. 44).

Hume e Aristóteles correlacionam o termo "bem" com os desejos e com os objetos de desejo. Para um humiano, o correlato e o objeto de desejo é a satisfação. Para um aristotélico, correlato e objeto de desejo é a perfeição, i.e., "aquilo que torna melhor a pessoa que deseja, aquilo que é, para ele, uma coisa boa" (FINNIS, 2012, p. 44). É nessa esteira que Aristóteles afirma que desejamos algo porque parece bom para nós; não é que parece bom para nós porque nós o desejamos.

Finnis entende que Lonergan ignorou a diferença entre o bem como algo experienciado e o bem como algo inteligível. "Entendimento e sentimento estão, normalmente, tão integrados no nosso querer que facilmente podemos ignorar ou mal compreender essa distinção" - a diferença é entre o puro querer (sentimento) e o querer algo (para obter, ser, ter ou fazer) "relacionado a uma descrição" - o querer inteligente (FINNIS, 2012, p. 45).

A inteligência não é apenas contemplativa, mas também é prática, o que significa que (1) pode perseguir um objetivo indo de encontro a desejos ou emoções; (2) pode revisar projetos à medida que o sujeito interage com outras pessoas em um determinado curso de ação; (3) pode prover muitas formas de realizar o bem a partir de circunstâncias identificadas.

\section{A INTEGRAÇÃo do SENTIMENTO À RAZÃo PRÁtiCA E A ALEgORIA dA MÁQUINA DE EXPERIÊNCIAS IRRACIONAIS}

Como se percebe, Finnis não pretende estabelecer uma dicotomia estanque entre desejos e razão prática; ao contrário, pretende integrá-lo à razoabilidade da ação inteligente porque direcionada a um bem verdadeiro, que, por ser bom, é desejável. Por isso, a busca pelo bem inteligível não precisa estar em competição ou isolamento em relação aos sentimentos e experiências. Antes, o desejo deve participar da ação inteligente de percepção e realização do bem inteligível: "essa emoção ou sentimento é um aspecto da sua realidade enquanto bem humano. [...] não se participa plenamente desses bens a menos que eles sejam experienciados [emocional e subjetivamente] enquanto bens." (FINNIS, 2012, p. 47-48).

A emoção, portanto, é um aspecto da realização do bem. Um aspecto da perfeição do moralmente bom é que o agente seja movido ao bem não apenas pela vontade, mas também pelo desejo senciente (FINNIS, 1998, p. 75, nota 57). A participação sem emoção, porém, 
Artigo: Razão prática entre desejo e bens humanos básicos. A crítica metaética de John Finnis ao emotivismo e ceticismo

ainda é significativa. Considere, por exemplo, uma criança que é obrigada a ir para a escola aprender a ler - o aperfeiçoamento alcançado por meio da instanciação do bem do conhecimento no aprendizado é valoroso e significativo, ainda que a criança não esteja experimentando a situação dessa maneira, naquele momento. Todavia, a participação plena nos bens requer que sejam experienciados enquanto bens, ainda que o poder de discernimento inteligente e de desejo inteligente necessários para se agir inteligentemente possa ser subvertido pela "experiência tremendamente possessiva dos sentimentos" (FINNIS, 2012, p. 48).

Proposta por Robert Nozick, a alegoria da máquina de experiências é uma boa ilustração para a compreensão do papel das ações na constituição do indivíduo e diferenciação do campo inteligível e sentimental, demonstrando que é o primeiro, e não o último, que atribui valor à vida humana. Trata-se do seguinte experimento de pensamento: suponha que seu cérebro pudesse ser conectado com uma máquina de experiências, e que, enquanto seu corpo flutua num líquido dentro do tanque da máquina, seu cérebro seria estimulado com todas as experiências que você quisesse. A única condição é que uma vez conectado, você permaneceria conectado por toda a vida. Nesse caso hipotético, ou você se conecta por toda a vida ou nunca se conecta.

A recusa em conectar-se à máquina de experiências demonstra que (1) a atividade, a ação humana, possui sua própria razão de ser em um campo que está além do puro subjetivismo e dos sentimentos; (2) a manutenção da própria identidade é um bem e não é puramente sentimental, mas depende da ação humana; (3) as aparências não são um bem que substituam a realidade. A vida do sentimento interior não é tudo o que importa, e o prazer ou a experiência emocional não é a razão de ser da existência humana. Se o contrário fosse verdade, nos conectarmos à máquina seria o auge da realização humana, mas não é assim - “a vida de prazeres não pode contar como uma vida de realizações” (FINNIS, 2012, p. 38).

Em primeiro lugar, rejeitamos a máquina de experiências porque nosso entendimento prático indica que o bem deve ser encontrado na atividade. Mesmo a contemplação ou a espera são diferentes da passividade pura inerente a uma experiência desprovida de atividade. $\mathrm{Na}$ máquina, a pessoa não teria alcançado, nem realizado nada - ainda que tivesse a experiência de ter escrito um livro ou construído uma casa. Poderia ser dito que, do momento em que a pessoa foi conectada ao momento de sua morte, ela nunca viveu (FINNIS, 2012, p. 39). 
A vida de felicidade ou florescimento (eudaimonia) é uma vida de atividade (contemplativa ou ativa) - conforme o preceito inspirado na ética aristotélica: o florescimento é para ser encontrado na ação (omne ens pesficitur in actu). A razão fundamental para a atividade humana (mesmo quando a atividade é realizada para produzir outra coisa) é a atividade propriamente dita (FINNIS, 2012, p. 39).

Em segundo lugar, a rejeição de se conectar à máquina de experiências também é justificável porque a manutenção da própria identidade é um bem. Após um longo tempo, a imersão na máquina de experiências torna impossível identificar que tipo de pessoa a pessoa imersa na máquina é - será ela gentil ou corajosa?

Não há resposta para essas perguntas, não apenas porque seja difícil responder com precisão, mas porque não há nenhuma maneira que a pessoa seja. Conectar-se à máquina é um tipo de suicídio (FINNIS, 2012, p. 40). Consideramos que isto, per se, já aponta que existe uma relação substancial entre nossas ações e nossa identidade. Apesar de as pessoas existirem como seres humanos, elas só existem como corajosas, ou medrosas em ação. No campo da identidade, a chave de compreensão e construção do sujeito poderia ser apresentada não a partir do "penso, logo existo", mas como "ajo, logo sou quem sou".

Ainda nesse diapasão, Finnis considera que o princípio de Aristóteles (2007, p. 272) segundo o qual ninguém escolhe possuir o mundo inteiro se ele, primeiramente, tem que se tornar outra pessoa preocupa-se com o bem, não apenas de ser o que somos, mas de ser quem se é (FINNIS, 2012, p. 40-41). Todas as escolhas livres de alguém servem para constituir aquele alguém na pessoa que ela é, de modo que seu caráter ou identidade é a realização que é mais inequivocamente sua.

Ser quem se é é algo construído na atividade - as ações do sujeito realizam não apenas as suas "conquistas", mas, em um nível mais relevante, realizam ele mesmo. Esse pensamento transparece na seguinte afirmação: "não importa o que fizeram com você, mas o que você está fazendo com o que fizeram com você”. Essa afirmação em particular refere-se a situações difíceis vividas por alguém e sugere que, mesmo em contextos assim, ainda existe amplo espaço para escolhas que determinarão o curso de vida e identidade do sujeito: vingança ou perdão? Amargura ou liberdade? Em certo sentido, os seres humanos são senhores de si mesmos e serão o que fizerem de si próprios. Por isso que a construção da própria identidade é, de fato, a realização que mais inequivocamente pertence ao agente. Naturalmente, há bons e maus caracteres, mas a autoconstituição e a autenticidade, integrantes do bem da 
Artigo: Razão prática entre desejo e bens humanos básicos. A crítica metaética de John Finnis ao emotivismo e ceticismo

razoabilidade prática, merecem ser preservados como formas da ação humana, ainda que desenvolvidos para fins que são maus ou desarrazoados do ponto de vista substancial.

Em terceiro lugar, a rejeição da máquina de experiência demonstra que as aparências não são um bem que substituam a realidade. A rejeição da máquina implica o princípio central da ética de Platão segundo o qual a realidade é para ser preferida ao invés das aparências. Na máquina de experiências não há nenhum contato verdadeiro com a realidade - escolhê-la é "enterrar-se em um túmulo muito mais profundo do que a caverna de Platão" (FINNIS, 2012, p. 41).

Os habitantes da caverna estavam em contato com o mundo real de outras pessoas e poderiam se comunicar com aqueles que ascenderam da caverna e depois voltaram. Existe uma diferença entre estar em contato com o mundo real e ter a experiência do contato com a realidade. Essa diferença não é apreendida nos sentimentos, nem nas experiências. Os sentimentos e as experiências estão igualmente presentes no mundo real e nas induções provocadas no cérebro pela máquina.

Estar em contato com o mundo real e ter a experiência completa do contato com a realidade são coisas distintas. Todavia, essa distinção não pode ser alcançada em termos de experiência, de sentimentos, haja vista que em ambas as situações a experiência e os sentimentos são iguais. Não obstante, a diferença persiste e somos capazes de percebê-la por meio de nossa inteligência crítica. Conseguimos compreender essa diferença e sua importância. "Entendemos que é profunda, real e importante a distinção entre a vida real efetivamente vivida e a passividade autoimoladora de 'uma massa indeterminada' flutuante no tanque de experiências" (FINNIS, 2012, p. 42). Essa compreensão revela um aspecto da realidade que não pode ser reduzido às emoções ou experiências, um aspecto que é alcançável pelo espectro da inteligência. A razão alcança bens inteligíveis - o contato com a realidade é um bem inteligível e não meramente sentimental.

Essa reflexão sobre a máquina de experiências ajuda a acentuar e esclarecer a diferença entre bens experienciais e bens humanos como inteligíveis - podemos optar por realizar um bem que envolve a vida corporal e recebe todo tipo de experiência ao nos conectarmos com a máquina, porém a plena compreensão desse bem, sua plena medida e conteúdo, é perceptível enquanto tal somente por meio da inteligência (FINNIS, 2012, p. 42). Isso porque a inteligência capta os bens que realizam a natureza humana e dirige à sua realização. Essa é uma compreensão da razão prática completamente diferente da defendida por Hume, que denuncia a falsidade e restrição desarrazoável desta última, assim como 
desqualifica, prima facie, qualquer argumentação hedonista pautada somente na realização a partir de prazeres.

\section{A NATUREZA DA DELIBERAÇÃO E A AUTORREFUTAÇÃO CÉTICA}

A motivação para o agir humano é constituída por critérios racionais, e não sentimentais, sobre o que é verdadeiramente digno de ser escolhido. A posição cética contrária nega a inteligibilidade dos bens humanos a que racionalmente estamos inclinados, reduzindo a compreensão da ação humana às emoções ou aos sentimentos subjetivos, os quais seriam racionalizados pela linguagem (emotivismo).

O argumento cético também pode ser refutado a partir da análise estrutural do processo deliberativo e decisivo. Isto é, os elementos primários de uma resposta razoável às dúvidas céticas sobre verdade prática podem ser alcançados pela compreensão da constituição e execução de escolhas livres. Essa parte pretende demonstrar, portanto, a inconsistência interna do argumento cético pautado na razão prática humiana, o qual será postulado nos seguintes termos: "a ação humana é motivada por critérios sentimentais sobre o que é verdadeiramente digno de ser escolhido" (FINNIS, 1998, p. 58).

Inicialmente, convém observar que esse argumento cético emotivista - o de que a ação humana é motivada por critérios sentimentais sobre o que é verdadeiramente digno de ser escolhido - não é apresentado como uma opinião arbitrária, mas como um juízo verdadeiro. Além disso, a proposição é formulada como uma conclusão e não como algo autoevidente, portanto é necessário que premissas sejam postuladas e um argumento seja coerentemente construído para sustentar a conclusão. A proposição não se confunde com um argumento de ceticismo radical do tipo todas as opiniões são meras opiniões e não verdades, o qual é obviamente autorrefutável. Antes, é uma afirmação que pressupõe que há alguma verdade em jogo (FINNIS, 1998, p. 59).

Alguém que considera se deve ou não concordar com a proposição cética acima supõe que seria bom descobrir essa verdade, ainda que fosse emocionalmente desconfortável. Se a ação humana fosse motivada apenas por critérios sentimentais, o desconforto causado pela descoberta de uma verdade que contraria uma posição anterior seria o suficiente para que a descoberta fosse rejeitada - apesar de que isso possa acontecer para pessoas viciosas, imaturas e/ou fragilizadas. Mas não é assim que, em regra, as coisas acontecem na realidade objetiva. 
Artigo: Razão prática entre desejo e bens humanos básicos. A crítica metaética de John Finnis ao emotivismo e ceticismo

Não é incomum que, percebendo intelectualmente boas razões, apesar do desconforto emocional, as pessoas revisem seus próprios conceitos e planos, desprezando a opinião anterior e abraçando uma nova concepção com base no que consideram mais razoável. Além disso, a própria formulação do argumento não pressupõe que a proposição motive a ação humana a partir de critérios emotivos. Antes, o postulante da proposição cética deseja que seu postulado seja aceito a despeito dos sentimentos contrários do seu interlocutor, isso porque a verdade identificada não é apenas outro sentimento, mas um conhecimento inteligente que, enquanto tal, é digno de ser aceito.

$\mathrm{O}$ conhecimento é um bem inteligível e não meramente apelativo às emoções. A relação entre entendimento e realidade é alcançável apenas pela inteligência - que apreende os bens inteligíveis - e ela fornece sentido e propósito às atividades cognitivas que instanciam o bem do conhecimento. É por isso que atos como leitura e reflexão não são apenas emocionalmente satisfatórios, mas são razões últimas para a ação, porque realizam um bem humano básico.

Isso significa que a atividade intelectual possui sentido intrínseco próprio e não meramente instrumental - apresenta-se como um motivo para a própria ação cognoscitiva. Essa razão para agir é uma motivação que não é nem exclusivamente uma tensão ou atração para a satisfação emocional, nem meramente instrumental a algum outro objetivo racional. Reconhecer essa razão é entender o valor, o bem inteligível, presente em uma possibilidade de ação (FINNIS, 1998, p. 59).

A possibilidade que antecipa a realização de um bem é uma oportunidade de aperfeiçoamento. Se o bem for ignorado, a pessoa estará privada, deficiente, pior. Descobrir a verdade sobre o argumento cético constitui um aperfeiçoamento, e não a descobrir, uma imperfeição. Logo, a decisão de descobrir a verdade sobre o ceticismo ético vale a pena - tem valor intrínseco.

Finalmente, a afirmação de que nada é realmente, objetivamente, digno de ser escolhido é evidência suficiente de sua própria falsidade. A proposição cética analisada insiste que a motivação da ação humana são critérios subjetivos sobre o que é verdadeiramente digno de ser escolhido. Se isso fosse verdade, a tentativa de postular inteligentemente essa proposição, argumentar sobre ela, defendê-la social ou filosoficamente não faria sentido, do ponto de vista lógico.

$\mathrm{O}$ apelo à inteligibilidade, à lógica e ao argumento demonstra que a verdade da proposição depende de sua inteligência, e é esta inteligibilidade que deve motivar o 
interlocutor a aderir à posição cética. A estrutura autorrefutável em cada caso é essencialmente a mesma: a razoabilidade de levar essas asserções a sério e tratá-las como algo que oferece razões para que alguém passe tempo refletindo sobre o seu conteúdo é inconsistente com o próprio conteúdo (FINNIS, 1998, p. 60).

Os motivos para agir, o fim inteligível, o propósito intrínseco, e o bem compreensível são conceitos relacionados e interligados no processo de deliberação e escolhas, exatamente porque esse processo é levado adiante pela razão prática que apreende os bens humanos básicos e dirige a partir da fórmula o bem é para ser buscado e realizado, e o mal é para ser evitado, que expressa o primeiro princípio da razão prática, do qual derivam os primeiros princípios da razão prática que são os bens humanos básicos (GRISEZ, 1965).

Com efeito, como indicado na Introdução deste Artigo, esse argumento remonta a um texto inicial de Finnis (2011c), 'Autorrefutação cética', de 1973, retomado na sua obra mais influente, Lei natural e direitos naturais (FINNIS, 2011a). Nela, a exposição sobre a autoevidência dos bens humanos básicos começa com o exemplo performático do conhecimento, precisamente o bem que se está instanciando ao se ler o livro. As proposições céticas se refutam a si mesmas, no momento mesmo em que são pronunciadas, como: "'Sei que nada sei'; 'Pode ser provado que nada pode ser provado'; 'Todas as proposições são falsas"” (FINNIS, 2011a, p. 74).

Tomemos a último exemplo para explicitar a circularidade e fragilidade do argumento cético. Ora, se todas as proposições são falsas, essa proposição também o é. Logo, pelo menos a proposição que afirma a falsidade de todas as demais não é falsa. Mas como ela afirma que todas o são, ela há de ser também. Portanto, para que todas as proposições sejam falsas, é necessário que a proposição que explicite essa realidade esteja fora do alcance de si mesma. Portanto, é falsa, se for verdadeira; e é verdadeira, se for falsa. Nisso, consiste a autocontradição filosófica: ao se projetar sobre si mesma, a proposição perde a sua validade, sua consistência lógica.

Em 'Self-Retutation Revisited', de 2005, quando reflete sobre esse argumento que o acompanha por toda a obra - e cujos momentos de maior densidade filosófica são Fundamento de ética (FINNIS, 2012) e Aquinas (FINNIS, 1998), precisamente os textos de que mais nos valemos neste Artigo -, Finnis (2011d, p. 81) afirma que, se lhe fosse perguntado, ou melhor quando se pergunta sobre qual é a melhor advertência filosófica para os que desejam considerar Platão, Aristóteles e Aquino como mestres efetivos, a sua resposta seria: assegurar-se de que os argumentos propostos e defendidos são consistentes com o fato 
Artigo: Razão prática entre desejo e bens humanos básicos. A crítica metaética de John Finnis ao emotivismo e ceticismo

mesmo de postulá-los, e com o fato que se considera bom investigá-los, aceitá-los e propô-los aos assentimento de outros. Provavelmente a maioria das posições filosóficas, mesmo as dos filósofos mais reputados, não resistem a esse teste lógico de coerência interna, recaindo na falácia da autorrefutação.

A contradição lógica também pode ser performativa, quando alguém, falando, afirma que não sabe falar. Ou, mais radicalmente ainda, quando alguém afirma que não existe, sendo que a existência está pressuposta no fato de alguém poder afirmar algo. Ora, ao declarar que o conhecimento não é um bem, o cético se refuta, operacionalmente, a si mesmo. Ao postular essa afirmação - de que o conhecimento não é um bem -, o cético pretende, efetivamente, conhecer a verdade do alcance e do limite do conhecimento. Ou seja, ele pressupõe, formalmente, que há uma verdade a ser descoberta e comunicada, em cuja investigação e divulgação ele está engajado. Mas o conteúdo encontrado e expresso (o conhecimento não é um bem humano básico, ou não há bens humanos básicos) é contraditório com a forma pressuposta pela própria ação de afirmar algo (o conhecimento é um bem fundamental a ser buscado e realizado).

Muito pode ser aduzido contra a teoria da lei natural de Finnis, mas não que ela recai em contradição lógica com suas próprias premissas.

\section{CONCLUSÃO}

Atualmente, existe hesitação em se aceitar teorias abrangentes sobre o bem humano. Antes, há uma maior aceitação de teorias restritas. Uma teoria sobre o bem humano é restrita "se, e somente se, ela tem a intenção de identificar, enquanto bens humanos básicos, os bens de que qualquer ser humano precisa, quaisquer que sejam seus objetivos" (FINNIS, 2012, p. 49), isto é, sem fechar uma concepção sobre a boa vida. O título "teorias restritas" vem de John Rawls e é usado por ele para identificar sua própria teoria dos bens humanos. Teorias restritas são aceitas e motivadas pelo medo de políticas autoritárias que ameaçariam a liberdade e a autenticidade (FINNIS, 2012, p. 50).

Finnis se opõe a teorias restritas, que acabam subsidiando uma posição moral e política liberal ou libertária, e argumenta que tais teorias castram o entendimento reflexivo sobre a objetividade dos bens a partir do medo da ameaça à liberdade e à autenticidade. $\mathrm{Na}$ realidade, são as teorias restritas que são arbitrárias, pois elegem bens para servirem de matriz à persecução de desejos subjetivos e satisfações (ignorando o aspecto substancial do bem 
inteligível), ao mesmo tempo em que ignoram uma gama de possibilidades humanas ou as tratam como se fossem questões de gosto em vez de bens reais (FINNIS, 2012, p. 50).

Assim, teorias restritas pressupõem uma visão reducionista da razão prática. A imposição de teorias restritivas rompe pela raiz o perscrutar ético, pois permite imposições arbitrárias na busca prática por bens verdadeiros, e esta atitude revela não apenas uma redução da razão prática, mas do próprio ser humano, cuja racionalidade substancial é desprezada, dando lugar a uma concepção mecanicista, materialista da natureza humana - uma natureza voltada apenas a experiências sensíveis, relativas a cada agente moral.

Essas concepções restritivas têm desdobramentos no debate público, excluindo argumentos sem analisar o mérito deles, configurando uma censura arbitrária e desarrazoada. Finnis (2011, p. 71) menciona autores liberais como Rawls, Dowkin e Nagel como debitários de uma metaética cética, ainda que neguem suas concepções emotivistas, subjetivistas ou perspectivistas. Eles alegam que sua defesa pela neutralidade moral do Estado baseia-se, exclusivamente, em direitos políticos e no valor da dignidade da autonomia individual. Porém, quando se analisa a fundo a concepção de razão pública deles, percebe-se o atomismo social pautado num emotivismo cético. Daí a importância da reflexão ética de Finnis, não só para a teoria moral em geral, mas para o debate público sobre o bem comum, sobre o que, de fato, é o florescimento humano em sociedade.

Assim, este artigo apresenta a concepção metaética de razão prática em confronto dialético com o emotivismo e o ceticismo, introduzindo o fundamento filosófico principal da teoria da lei natural de John Finnis. Sua intenção também é a de abrir a reflexão jurídica e política do bem comum que se segue a essa ética dos bens humanos básicos. Uma vez reconhecida a insuficiência do emotivismo e do ceticismo subjacentes às teorias liberais e positivistas em geral, devem-se buscar teorias morais mais consistentes, que consigam descrever e avaliar o comportamento humano a partir de seus fundamentos racionais. $\mathrm{O}$ cognitivismo moral de Finnis apresenta uma relevância epistêmica que não pode ser negligenciada.

\section{REFERÊNCIAS}

ANNAS, Julia; BARNES, Jonathan. The modes of scepticism. Ancient texts and modern interpretations. Cambridge: Cambridge University Press, 1985.

ANSCOMBE, Elizabeth. Modern Moral Philosophy. In: Human life, action and ethics. Exeter: Imprint Academic, 2005. 
Artigo: Razão prática entre desejo e bens humanos básicos. A crítica metaética de John Finnis ao emotivismo e ceticismo

ALEXY, Robert. Una concepción teórico-discursiva de la razón práctica. In: El concepto y la validez del derecho. Tradução Jorge Seña. 2. ed. Barcelona: Gedisa, 1994. p. 131-157.

AQUINO, Tomás de. A pedagogia divina pela lei (questões 90-97). In: Suma teológica. v. 4: I Seção da II Parte, questões 49-114. Coordenação Carlos-Josaphat Oliveira. 2. ed. São Paulo: Loyola, 2010.

ARISTÓTELES. Ética a Nicômaco. Tradução Edson Bini. 2. ed. São Paulo: Edipro, 2007.

FERREIRA NETO, Arthur Maria. Metaética e a fundamentação do direito. Porto Alegre: Elegantia Juris, 2015.

FINNIS, John. Fundamentos de ética. Tradução Arthur M. Ferreira Neto. Rio de Janeiro: Elsevier, 2012.

FINNIS, John. Natural law and natural rights. 2. ed. New York: Oxford University Press, 2011a.

FINNIS, John. Introduction. In: Reason in action. Collected Essays: vol. I. Oxford: Oxford University Press, 2011b. p.1-15.

FINNIS, John. Scepticism's Self-Refutation (1977). In: Reason in action. Collected Essays: vol. I. Oxford: Oxford University Press, 2011c. p. 62-80.

FINNIS, John. 4. Self-Refutation Revisited (2005). In: Reason in action. Collected Essays: vol. I. Oxford: Oxford University Press, 2011d. p. 81-91.

FINNIS, John. Prudence about ends (1997). In: Reason in action. Collected Essays: vol. I. Oxford: Oxford University Press, 2011e. p. 173-186.

FINNIS, John. Natural law (1996). In: Reason in action. Collected Essays: vol. I. Oxford: Oxford University Press, 2011f. p. 199-211.

FINNIS, John. Secularism's practical meaning (1998). In: Religion and public reasons. Collected Essays: vol. V. Oxford: Oxford University Press, 2011g. p. 56-79.

FINNIS, John. Religion and state (2006). In: Religion and public reasons. Collected Essays: vol. V. Oxford: Oxford University Press, 2011h. p. 80-102.

FINNIS, John. Aquinas: moral, political and legal theory. New York: Oxford University Press, 1998.

GEORGE, Robert P. Making men moral: civil liberties and public morality. Oxford: Clarendon Press, 1993.

GRISEZ, Germain. The First Principle of Practical Reason: A Commentary on the Summa Theologiae, 1-2 Question 94, Article 2. Natural law forum, vol. 10, 1965, p. 168-201. 
GRISEZ, Germain; FINNIS, John; BOYLE, Joseph. Practical principles, moral truth and ultimate ends. American Journal of Jurisprudence, v. 32, 1987, p. 99-151.

HUME, David. Tratado da natureza humana. Uma tentativa de introduzir o método experimental de raciocínio nos assuntos morais. Tradução Déborah Danowski. 2. ed. amp. e rev. São Paulo: Ed.UNESP, 2009.

KEOWN, John; GEORGE, Robert P. (eds.). Reason, morality, and law: The philosophy of John Finnis. Oxford: Oxford University Press, 2013.

MACINTYRE, Alasdair. Depois da virtude: um estudo em teoria moral. Tradução Jussara Simões. Bauru: EDUSC, 2001.

MAHON, James Edwin. MacIntyre and the Emotivist. In: O’ROURKE, F. (ed.) What happened in and to moral philosophy in the twentieth century? Philosophical essays in honor of Alasdair MacIntyre. Indiana: University of Notre Dame Press, 2013.

MASSINI-CORREAS, Carlos I. Iusnaturalismo, razón práctica y objetividade del derecho. In: La ley natural y su interpretación contemporánea. Pamplona: EUNSA, 2006.

MENDONÇA, Wilson. Metaética. In: TORRES, João Carlos Brum. Manual de ética. Questões de ética teórica e aplicada. Petrópolis: Vozes, 2014, p. 153-173.

MIRANDA, John Florindo de. Da lei natural como fundamento supramoral da ação humana em John Finnis: Considerações sobre metodologia, teoria normativa e aspectos fundacionais. Dissertação [Mestrado em Filosofia]. Instituto de Filosofia, Sociologia e Política da Universidade Federal de Pelotas, Pelotas, 2015.

RIST, John. Real ethics. Reconsidering the foundations of morality. Cambridge: Cambridge University Press, 2002.

VIGO, Luis Rodolfo. La democracia: conjuga mejor con el objetivismo y el cognitivismo moral o con el escepticismo y el relativismo (Kelsen-Ferrajoli versus Nino-Moreso)?. In: Iusnaturalismo y neoconstitucionalismo. Coincidencias y diferencias. Buenos Aires: Universidad Católica Argentina, 2015. p. 465-470. 